\title{
Agronomic Performance of Transgenic and Non Trangenic Cotton Against Cotton Leaf Curl Virus
}

\author{
Rana Faisal Iqbal ${ }^{1, *}$, Mubasher Ali ${ }^{2}$, Jamil Shafi ${ }^{2}$, Waqas Ahmad ${ }^{3}$, Muhammad Atiq ${ }^{2}$, Muhammad \\ Mohsin $^{2}$, Muhammad Shahid ${ }^{1}$ \\ ${ }^{1}$ Department of Plant Breeding and Genetics, University of Agriculture Faisalabad (38040) Pakistan \\ ${ }^{2}$ Department of Plant Pathology, University of Agriculture Faisalabad (38040) Pakistan \\ ${ }^{3}$ Institute of Horticultural Sciences, University of Agriculture, Faisalabad (38040) Pakistan \\ *Corresponding Author: uaf3840@gmail.com
}

Copyright $@ 2013$ Horizon Research Publishing All rights reserved.

\begin{abstract}
The present study was carried out to increase the level of tolerance in Gossypium hirsutum L. against cotton leaf curl disease (CLCuD). Hybridization of a transgenic line (anti-sense tRep gene) with three naturally resistant (non-transgenic) varieties namely FH-1000, MNH-786 and NIBGE-115 was performed. The parents and their F1 Hybrids were evaluated for disease infectivity. Data of some morphological traits (Plant Height, Monopodial Branches per Plant, Sympodial Branches per Plant, Number of Boll per Plant, Lint Percentage, Boll Weight, Staple Length, Staple Strength, Fiber Fineness, Yield of Seed Cotton ) was evaluated satanically to check the influence of disease on morphology of plant. The results showed that hybridization increased the tolerance level against cotton leaf curl virus.
\end{abstract}

Keywords Gossypium Hirsutum L., Hybridization, Transgenic, Non-Transgenic.

\section{Introduction}

Cotton (Gossypium hirsutum L.) belongs to Gossypium family. Gossypium includes 52 species Out of which 48 are wild and four are cultivated which produce spinnable fiber. The cultivated species include two diploids, G. herbaceum $L$. and $G$. arboreum $L$., and two other, G. barbadense $L$. and $G$. hirsutum $L$ are tetraploids. Cotton (Gossypium hirsutum L.) plays leading role in the economy all over the world that is why it is known as "silver fiber" among various farmer communities [1]. Cotton leaf curl disease (CLCuD) is a main threat to cotton worldwide and is an important factor in limiting the yield $[2,3]$.

The causal organism of CLCuD is a virus named after the typical symptom of disease (leaf curling, leaf enation) as cotton leaf curl virus (CLCuV), a begomovirus. These are plant viruses that belong to the family Geminiviridae, and are characterized by the unique Gemini shape of a fused icosahedral viral particl [4]. According to their genome organization they may be monopartite or bipartite having one or a pair of circular ssDNA molecules respectively $[5,6]$. The members of genus Begomovirus are the causel organisms for a variety of economically important diseases. This genus consist of about 200 species [7]. Whitefly $B$. tabaci is a vector for their transmission $[8,9]$.

$\mathrm{CLCuD}$ showed typical symptoms, which includes leaf curling and in severe cases leaves attain cup shape, veins of infected leave swells and darkening those infected veins and enations of leaf underneath infected leaves [10. 11, 12, 8]. Infection to plant caused by CLCuD varies due to varietal difference, vector density and climatic factors in an area. Reduction in yield due to the adoption of tolerant varieties has been recorded up to $50 \%$ and in comparison growing of susceptible varieties reduced the yield to $85 \%-90 \%$ [13].

The transgenic plants used in the studies were developed through gene silencing technique known as RNA interference (RNAi) [14]. An approach has developed to express antisense transgenes complimentary to target mRNA. Experimentation on different antisense transgens proves that specific resistance could be attained through homologous antisense RNA and the target virus sequence [15]. The technology of anti-sense RNAi has been successfully applied to engineer resistance against geminiviruses [16,17]. Antisense is actually very complex pathways found in nature for gene regulation through homologous sensing mechanism. In this method sense transcripts are also able to silence gene expression [18]. Recently transgenic tobacco plants expressing geminiviral resistance to the $\mathrm{CLCuV}$, through the expression of truncated tAC1/tRep gene of $\mathrm{CLCuV}$ in sense and antisense orientation and blocked the replication of this virus through RNAi [15].

Broad-spectrum resistance could be produced by combining multiple sources of resistance, i.e. hybridization of naturally tolerant and genetically engineered plants [19, 20]. To achieve that goal a breeding program was planned involving transgenic plants with expressed tRep gene and naturally tolerant varieties already present in field. 


\section{Materials and Methods}

The present study was carried out to estimate the level of tolerance transgenic cotton, naturally tolerant cultivars and there $F_{1}$ generation against cotton leaf curl virus at National Institute for Biotechnology and Genetic Engineering (NIBGE), during year 2011-2012

Seeds of transgenic cotton with anti-sense tRep gene in expressed and active form were collected from Gene Transformation Lab at NIBGE. Three naturally resistant varieties namely FH-1000, MNH-786 and NIBGE-115 were collected from Cotton Research Institute, Ayub Agricultural Research Institute (AARI), Faisalabad, Cotton Research Station, Multan and NIBGE respectably.

Four parents were planted in glasshouse at NIBGE. The plants were sown in earthen pots of $35 \times 40 \mathrm{~cm}^{2}$ dimensions to provide sufficient space for plant root and canopy to grow. Medium of plant growth consisted of $70 \%$ of sand and $30 \%$ of clay.

The transgenic Cotton plants were confirmed before hybridization through Polymerase Chain Reaction (PCR) by using gene specific primers.

The crosses were attempted in glasshouse in such pattern that the transgenic anti-sense tRep was used as male pollen producing parent and FH-100, MNH-786, NIBGE-115 were used as female pollinated from those pollens. To obtain sufficient amount of seed for F1 a maximum number of crosses were made. The procedure and description of crosses was given as under:

\begin{tabular}{lll} 
Female Parents & \multicolumn{1}{c}{ Male Parents } \\
FH-1000 $\times$ & anti-sense tRep Coker-312 \\
MNH-786 $\times$ & anti-sense tRep Coker-312 \\
NIBGE-115 $\times$ & anti-sense tRep Coker-312
\end{tabular}

40 plants of each cross along with four parental lines (10 plants in four replications) were sown in glasshouse of NIBGE, Faisalabad. The parental material was sown along with F1 for proper estimation of tolerance level.

The seeds were dibbled to ensure uniform plant population. All necessary agronomic practices and plant protection measures were adopted including plowing, hoeing, proper irrigation and fertilizer application and pesticide application when required. These all measures were taken till the crop maturity to produce healthy crop.

The confirmation of presence of transgene was done with the PCR. The plants with the transgene were evaluated and those without transgene were discarded.

The Parental material and F1 plants were inoculated with $\mathrm{CLCuV}$ using whitefly as a natural vector. Whiteflies were collected from cotton plants infected from CLCuD from the field area of NIBGE and NIAB. A total of 280 pots of plants were inoculated using 50 viruliferous whiteflies per plant. After 4 days of inculcation, insecticide was applied on the pods to kill whiteflies [22].

The evaluation of tolerance level was done on the basis of visual observations and photographed with a high resolution camera. The photographs of healthy plants were compared with the photographs of diseased plants after 10 days of inculcation. After 15 days of inoculation infected plants were counted to estimate percent disease infectivity (\%DI) by the given formula [22].

Number of infected plants a genotype

$\% \mathrm{DI}=\longrightarrow 100$

Total number of plants of that genotype

\subsection{Assessment of Viral Infection on Agronomic Traits}

\subsubsection{Plant height $(\mathrm{cm})$}

When main stem of plants had ceased its epical growth, the maximum height of plant was shown. Height of five random plants was measured $(\mathrm{cm})$ using measuring scale from the base to the top in the pods. For statistical analysis average plant height was calculated.

\subsubsection{Number of Monopodial Branches}

The indirect fruit bearing vegetative branches which present near the base of main stem i.e. monopodia. These branches developed on each plant were counted from 40 plants of all parents and their families and the averaged for statistical analysis.

\subsubsection{Number of Sympodial Branches}

The reproductive branches are called sympodial branches, and bolls are formed directly on these branches. The erectness and spreading behavior of plants depend on the development of these branches. Number of the sympodia on individual plant bases was recorded and analyzed statistically.

\subsubsection{Number of Bolls Per Plant}

By nature cotton plant has indeterminate growth habit, and therefore number of bolls on each plant continues to develop over week was counted at each picking from growing to till harvest the crop. When all picking were completed, the total number of bolls was summed up. The unopened or diseased bolls also are counted. Mean number of bolls in each replicates were calculated for statistical analysis.

\subsubsection{Boll Weight}

Average boll weight of each plant was calculated dividing the seed cotton yield on number of bolls per plant of respective genotype. For the analysis the mean value of all the replicates was calculated.

\subsubsection{Yield of Seed Cotton}

Seed cotton was collected when the mature bolls were picked. Picking was done at noon and evening as the dew had evaporated. By using electrical balance all the picked seed cotton was weighted in grams, then the total weight of seed cotton was noted of each plant individually in all replicates. Average seed cotton yield of each genotype was calculated by dividing the number of plants of each genotype in a line.

\subsubsection{Lint Percentage}


By using single roller electrical gin in the ginning laboratory, all the plants of each genotype were ginned. Weighted the lint obtained after ginning the seed cotton of each plant. By applying the following formula lint percentage of all the genotypes were measured for analysis.

$$
\text { Lint percentage }=\frac{\text { Wt. of Lint in a sample }}{\text { Wt. of seed cotton in a sample }} \times 100
$$

\subsubsection{Fiber Characters}

Using computerized machine spinbal HVI 9000, different fiber characters like fiber strength, length, fineness and uniformity were measured of each plant. This computerized machine provides a complete comprehension profile of raw fiber in a very short time period. It measured the fiber characters according to international trading standards. Mean values of these characters were then calculated.

\subsection{Statistical Analysis}

Data collected was collected and analyzed statistically by using analysis of variance technique [23]. Duncan Multiple Range Test will be applied at $5 \%$ level of significance.

Phenotypic and genotypic coefficients of variation were calculated according to the formula given below:GCV $(\%)=$ Genotypic coefficient of variation

$$
\operatorname{GCV}=\frac{\sqrt{\sigma_{g}^{2}}}{\bar{x}} \times 100
$$

PCV $(\%)=$ Phenotypic coefficient of variation

$$
\mathrm{PCV}=\frac{\sqrt{\sigma_{\mathrm{P}}^{2}}}{\overline{\mathrm{X}}} \times 100
$$

Where:

$\bar{X}=$ Grand mean of the trait

$\sigma^{2} \mathrm{p}=$ phenotypic variance

$\sigma^{2} \mathrm{~g}=$ genotypic variance

Broad sense heritability $\left(\mathrm{h}^{2}{ }_{\mathrm{BS}}\right)$ for each recorded trait was calculated as a ratio of the genotypic variances to phenotypic variances.

$$
\mathbf{h}_{\mathrm{BS}}^{2}=\frac{\sigma_{\mathrm{g}}^{2}}{\sigma_{\mathrm{p}}^{2}}
$$

\section{Results}

\subsection{Confirmation of Transgenic Parental Line}

The confirmation of transgenic parental plants was necessary before hybridization to ensure the presence of antisense trep gene in disease free transgenic plants. The confirmation was done by amplifying the antisense tRep gene from total genomic DNA of transgenic plants with PCR
[24]. PCR amplify the tRep gene with the gene specific primers (forward and reverse). The sequence of antisense tRep primers for amplification of specific gene is given below:

\section{Forward primer (Position 2600-2581) 5-AGTCAACATGCCTCCAAAGC-3}

2. Reverse primer (Position 5-AGCTAGTTCCTTAATGACTC-3

The gene is the complimentary sequence of viral DNA A for the rep region of viral genome and cause interference in translation of RNA produced as a result of transcript of rep region in DNA A of viral genome [25].

After completion of PCR the product was run on agarose gel to visualize the amplification under UV light on gel documentation system. Pictures of the gel were taken to show the results and to maintain the record for further study. The length of amplified product was 466bp [15]. Bands of the product were formed just slightly lower than 500bp band (second step of $1 \mathrm{~Kb}$ leader) at $466 \mathrm{bp}$ and were clearly visible (Fig. 1).

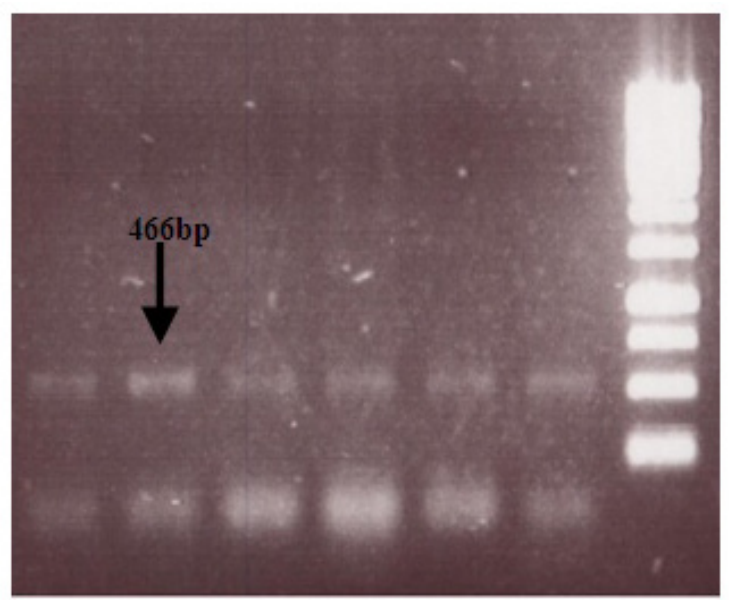

Figure 1. The band of $466 \mathrm{bp}$ provide with an evidence that amplification was of tRep gene confirming transgenic parental line

\subsection{Confirmation of Transgenes in $F_{1}$ Generation}

The investigation and confirmation of transgene of tRep was done after hybridization of transgenic and non-transgenic plants. The presence of tRep gene in $F_{1}$ generation proves the inheritance of antisense tRep gene. Increase in resistance level showed gene stability in $\mathrm{F}_{1}$ plants. The confirmation was done by PCR as previously performed in parental confirmation. The DNA extracted from all the families of $F_{1}$ generation was used with gene specific primers in a PCR reaction to amplify the gene sequence [24]. After completion, the PCR product was run on agarose gel to visualize any amplification under UV light on gel documentation system. Pictures of gel were taken display the results of confirmation and to maintain the record. The size of amplified product was $466 \mathrm{bp}$ as parental line had the band of same size [24]. Bands of the product were formed just 
slightly lower than $500 \mathrm{bp}$ band (second step of $1 \mathrm{~Kb}$ leader) at $466 \mathrm{bp}$ and were clearly visible. Fig. 2 showed the confirmatory gel picture of $F_{1}$ generation from the cross of FH-1000 $\times$ anti-sense tRep transgenic Cocker-312, Fig. 3 showed the confirmatory gel picture of $F_{1}$ generation from the cross of MNH-786 $\times$ anti-sense tRep transgenic Cocker-312 and Fig. 4 showed the confirmatory gel picture of $F_{1}$ generation from the cross of NIBGE-115 $\times$ anti-sense tRep transgenic Cocker-312 [24].

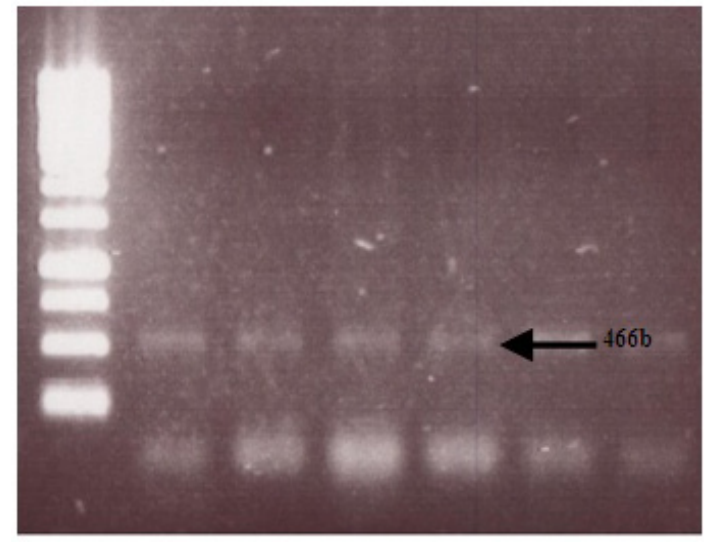

Figure 2. Band of $466 \mathrm{bp}$ provide the confirmation of transgenic anti-sense tRep gene in F1 of FH-1000 $\times$ anti-sense Cocker- 312

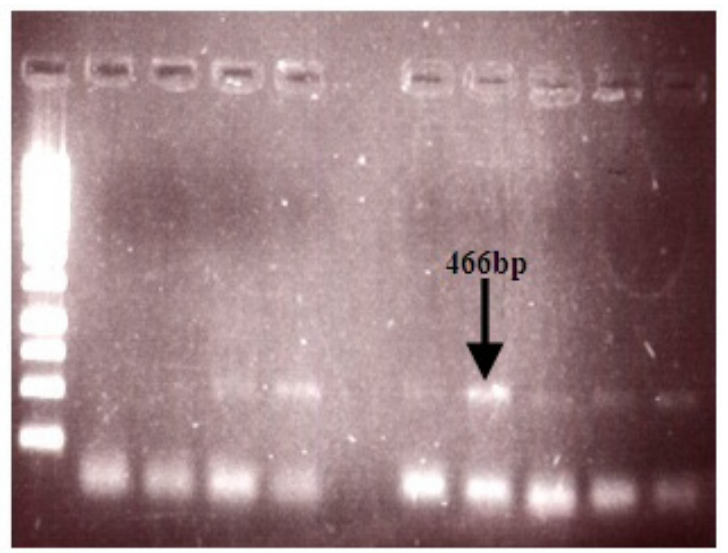

Figure 3. Band of $466 \mathrm{bp}$ provide the confirmation of transgenic anti-sense tRep gene in $\mathrm{F}_{1}$ of $\mathrm{MNH}-786 \times$ anti-sense Cocker-312

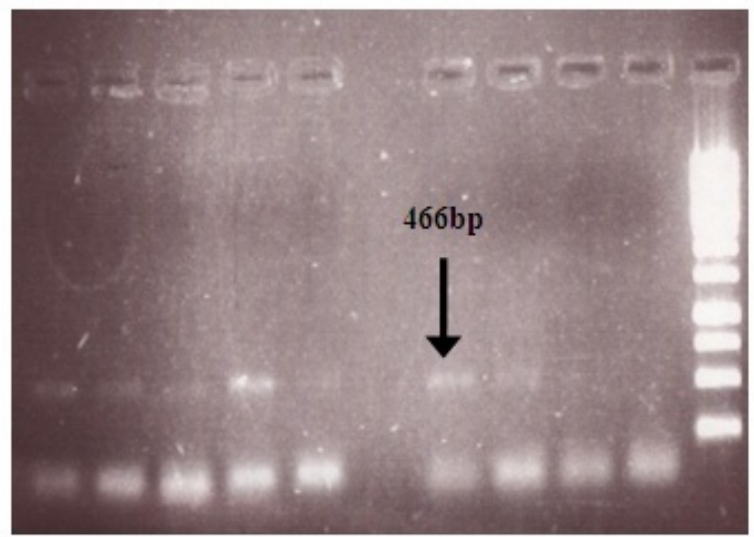

Figure 4. Band of 466bp provide the confirmation of transgenic anti-sense tRep gene in F1 of NIBGE-115 $\times$ anti-sense Cocker-312

\subsection{Disease Hot spots}

Table 1. CLCuV infestation within 15 days of Inoculation

\begin{tabular}{c|c|c|c|c}
\hline Genotype & $\begin{array}{c}\mathbf{5} \\
\text { Days }\end{array}$ & $\begin{array}{c}\mathbf{1 0} \\
\text { Days }\end{array}$ & $\begin{array}{c}\mathbf{1 5} \\
\text { Days }\end{array}$ & \%DI* \\
\hline FH-1000 & $3 / 40$ & $6 / 40$ & $8 / 40$ & 20 \\
\hline MNH-786 & $5 / 40$ & $7 / 40$ & $9 / 40$ & 22.5 \\
\hline NIBGE-115 & $4 / 40$ & $9 / 40$ & $14 / 40$ & 35 \\
\hline tRep Cocker-312 & $2 / 40$ & $5 / 40$ & $6 / 40$ & 15 \\
\hline $\begin{array}{c}\text { MNH-1000 } \times \text { tRep Cocker-312 } \\
\text { Cocker-312 }\end{array}$ & $3 / 40$ & $6 / 40$ & $7 / 40$ & 17.5 \\
\hline $\begin{array}{c}\text { NIBGE-115 } \times \text { tRep } \\
\text { Cocker-312 }\end{array}$ & $4 / 40$ & $7 / 40$ & $11 / 40$ & 27.5 \\
\hline
\end{tabular}

\subsection{Plant Height ( $\mathrm{cm}$ )}

Maximum plant height was observed (106.78) for MNH-786 followed by NIBGE-115. The mean value was minimum (96.8) for Anti-sense tRep cocker-312 (Table2).

The means of $F_{1}$ progenies for plant height were compared. The results after evaluation (Table 2) reveals that the mean value was maximum (101.79) for MNH-786 $\times$ Anti-sense tRep cocker-312 followed by NIBGE115 $\times$ Anti-sense tRep cocker-312 for plant height. The mean value was minimum (98.717) for FH-1000 × Anti-sense tRep cocker-312.

These results showed that plant height of $F_{1}$ generation was almost equal to their parental material. In all three crosses the hybrid of MNH-786 is performing better for this trait.

GV value was higher for plant height (10.521) for parental lines followed by the GV values of $F_{1}$ generation (1.286). The PV value was also higher (15.998) for parental lines followed by $F_{1}$ generation (5.256). The EV value was higher (5.476) for parental lines followed by $F_{1}$ generation (3.970) (Table 2).

For plant height GCV value was higher (3.167) for parental lines followed by $F_{1}$ generation (1.128). The PCV value was higher (3.905) for parental lines followed by $F_{1}$ generation (2.280). The ECV value was higher (2.285) for parental lines followed by $F_{1}$ generation (1.981) (Table 3).

The higher GCV value for parental lines indicates that the plant height of parental lines is better than $F_{1}$ generation. Hence on the basis of this genotypic variance component Plant height of $F_{1}$ may be improved by breeding for particular trait.

There was high heritability $(0.657)$ found for parental lines followed by $F_{1}$ generation (0.244). The high value of heritability of parents for plant height suggests that selection might be done among the parental genotypes.

The high GV, PV, GCV and PCV values indicate that variation is present but we are not sure rather this variation is useful or not. Results suggest that $F_{1}$ must be used in future breeding program for improvement. 


\subsection{Monopodial Branches Per Plant}

Monopodial branches per plant was maximum (1.5333) for MNH-786 and reaming three lines had the mean value 1.4. The mean value for remaining three lines was same (1.4).

Maximum Monopodia branches per plant was (1.4667) for MNH-786 $\times$ Anti-sense tRep cocker-312 followed by NIBGE115 × Anti-sense tRep cocker-312 for monopodial branches per plant. The mean value was same (1.4) for FH-1000 $\times$ Anti-sense tRep cocker-312 as well. These results showed that monopodial branches per plant of $\mathrm{F} 1$ hybrids are almost equal to their parental material. In all three crosses the hybrid of MNH-786 is performing better for this trait (Table 2).

The GV value was higher for monopodial branches per plant (0.002) for parental lines followed by the $\mathrm{GV}$ values of $\mathrm{F}_{1}$ generation (-0.001). The PV value was also higher (0.006) for $F_{1}$ generation followed by parental lines $(0.003)$. The EV value was higher $(0.007)$ for parental lines followed by $F_{1}$ generation (3.970) (Table 3).

For monopodial branches per plant GCV value was higher (2.791) for parental lines followed by $F_{1}$ generation $(0.0001)$. The PCV value was higher (5.495) for $F_{1}$ generation followed by parental lines (4.958). The ECV value was higher (5.857) for $F_{1}$ generation followed by parental lines (4.098) (Table 3).

The higher GCV value for parental lines indicates that the monopodial branches per plant of parental lines are better than $F_{1}$ generation. Hence on the basis of this genotypic variance component monopodial branches per plant of $F_{1}$ may be improved by breeding for particular trait.

There was high heritability $(0.317)$ found for parental lines followed by $F_{1}$ generation (-0.136). The high value of heritability of parents for monopodial branches per plant suggests that selection might be done among the parental genotypes.

\subsection{Sympodial Branches per Plant}

Sympodial branches per plant was maximum (20.533) for NIBGE-115 followed by Anti-sense tRep cocker-312 and was minimum (16.467) for FH-1000 (Table 2).

Sympodial branches was maximum (20.067) for NIBGE-115 $\times$ Anti-sense tRep cocker-312 followed by MNH-786 $\times$ Anti-sense tRep cocker-312 for sympodial branches per plant. The mean value was minimum (18.033) for FH-1000 $\times$ Anti-sense tRep cocker-312.

These results showed that Sympodial branches per plant of F1 hybrids are almost equal to their parental material. In all three crosses the hybrid of NIBGE-115 is performing better for this trait (Table 2).

The GV value was higher for sympodial branches per plant (1.943) for parental lines followed by the GV values of $\mathrm{F}_{1}$ generation (1.038). The $\mathrm{PV}$ value was also higher (2.073) for parental lines followed by $F_{1}$ generation (1.105). The EV value was higher $(0.130)$ for parental lines followed by $F_{1}$ generation (0.067) (Table 2).

For sympodial branches per plant GCV value was higher (7.475) for parental lines followed by $F_{1}$ generation (5.375). The PCV value was higher (7.720) for parental lines followed by $\mathrm{F}_{1}$ generation (5.545). The ECV value was higher (1.930) for parental lines followed by $F_{1}$ generation (1.362) (Table 3).

The higher GCV value for parental lines indicates that the sympodial branches per plant of parental lines are better than $\mathrm{F}_{1}$ generation. Hence on the basis of this genotypic variance component sympodial branches per plant of $F_{1}$ may be improved by breeding for particular trait.

\subsection{Number of Boll per Plant}

Number of boll per plant was maximum (38.067) for FH-1000 followed by NIBGE-115. The mean value was minimum (33.6) for Anti-sense tRep cocker-312.

The Table 2 reveals that the number of boll per plant was maximum (35.833) for FH-1000 $\times$ Anti-sense tRep cocker-312 followed by NIBGE-115 $\times$ Anti-sense tRep cocker-312 for number of boll per plant. The mean value was minimum (34.333) for MNH-786 $\times$ Anti-sense tRep cocker-312.

These results showed that number of boll per plant of F1 hybrids are almost equal to their parental material. In all three crosses the hybrid of FH-1000 is performing better for this trait.

The Table 3 showed that for number of boll per plant the $\mathrm{GV}$ value was higher (1.325) for parental lines followed by the GV values of $F_{1}$ generation (-0.137). The PV value was also higher (4.088) for parental lines followed by $F_{1}$ generation (1.968). The EV value was higher (2.763) for parental lines followed by $F_{1}$ generation (2.104).

GCV for number of boll per plant value was higher (3.209) for parental lines followed by $F_{1}$ generation $(0.0001)$. The PCV value was higher (5.637) for parental lines followed by $F_{1}$ generation (3.995). The ECV value was higher (4.635) for parental lines followed by $F_{1}$ generation (4.131) (Table 3).

The higher GCV value for parental lines indicates that the number of boll per plant of parental lines is better than $F_{1}$ generation. Hence on the basis of this genotypic variance component number of boll per plant of $F_{1}$ may be improved by breeding for particular trait.

\subsection{Lint Percentage (GOT \%)}

Maximum lint percentage was (38.380) for NIBGE-115 followed by FH-1000. The mean value was minimum (34.640) for Anti-sense tRep cocker-312.

The Table 2 reveals that lint percentage was maximum (36.51) for NIBGE-115 $\times$ Anti-sense tRep cocker-312 followed by MNH-786 $\times$ Anti-sense tRep cocker-312 for lint percentage. The mean value was minimum (35.50) for FH-1000 $\times$ Anti-sense tRep cocker-312 (Table 2).

These results showed that lint percentage of F1 hybrids is almost equal to their parental material. In all three crosses the 
hybrid of NIBGE-115 is performing better for this trait.

The Table 3 showed that for lint percentage the GV value was higher (1.445) for parental lines followed by the GV values of $F_{1}$ generation $(0.272)$. The $P V$ value was also higher (1.528) for parental lines followed by $F_{1}$ generation (0.355). The EV value was higher (0.083) for parental lines followed by $F_{1}$ generation ( 0.083$)$.

GCV for lint percentage value was higher (3.278) for parental lines followed by $\mathrm{F}_{1}$ generation (1.453). The PCV value was higher (3.371) for parental lines followed by $F_{1}$ generation (1.660). The ECV value was higher (0.787) for parental lines followed by $F_{1}$ generation (0.804) (Table 3).

The higher GCV value for parental lines indicates that the lint percentage of parental lines is better than $F_{1}$ generation. Hence on the basis of this genotypic variance component lint percentage of $\mathrm{F}_{1}$ may be improved by breeding for particular trait.

\subsection{Boll Weight}

Maximum Boll Weight was recorded (3.7667) for Anti-sense tRep cocker-312 followed by NIBGE-115 and then FH-1000 and minimum (3.5733) for MNH-786 (Table 2).

The Table 2 expresses that the maximum (3.7667) boll weight was recorded for NIBGE-115 $\times$ Anti-sense tRep cocker-312 followed by FH-1000 $\times$ Anti-sense tRep cocker-312 for boll weight and minimum (3.67) for MNH-786 × Anti-sense tRep cocker-312.

These results showed that boll weight of F1 hybrids is almost equal to their parental material. In all three crosses the hybrid of NIBGE-115 is performing better for this trait.

The Table 3 showed that for Boll Weight the GV value was higher (0.004) for parental lines followed by the GV values of $F_{1}$ generation (0.002). The PV value was also higher $(0.008)$ for parental lines followed by $F_{1}$ generation (0.004). The EV value was higher (0.004) for parental lines followed by $F_{1}$ generation $(0.002)$.

For Boll Weight GCV value was higher (1.669) for parental lines followed by $\mathrm{F}_{1}$ generation (1.116). The PCV value was higher (2.370) for parental lines followed by $F_{1}$ generation (1.702). The ECV value was higher (1.683) for parental lines followed by $\mathrm{F}_{1}$ generation (1.284) (Table 3).

The higher GCV value for parental lines indicates that the Boll Weight of parental lines is better than $F_{1}$ generation. Hence on the basis of this genotypic variance component Plant height of $F_{1}$ may be improved by breeding for particular trait.

\subsection{Staple Length}

Staple length was maximum (35.187) for FH-1000 followed by NIBGE-115 and then MNH-786. The mean value was minimum (34.720) for Anti-sense tRep cocker-312 (Table 2).

The Table 2 reveals that the mean value was maximum (34.953) for FH-1000 $\times$ Anti-sense tRep cocker-312 followed by NIBGE-115 $\times$ Anti-sense tRep cocker-312 for staple length and was minimum (34.793) for MNH-786 $\times$ Anti-sense tRep cocker-312.

These results showed that staple length of F1 hybrids is almost equal to their parental material. In all three crosses the hybrid of FH-1000 is performing better for this trait.

GV value was higher for staple length the (0.896) for parental lines followed by the $\mathrm{GV}$ values of $F_{1}$ generation (0.461). The PV value was also higher (1.860) for parental lines followed by $\mathrm{F}_{1}$ generation $(0.943)$. The $\mathrm{EV}$ value was higher (2.756) for parental lines followed by $F_{1}$ generation (1.404) (Table 3).

For staple length GCV value was higher (0.001) for parental lines followed by $F_{1}$ generation $(0.0001)$. The PCV value was higher (3.904) for parental lines followed by $F_{1}$ generation (2.785). The ECV value was higher (4.752) for parental lines followed by $F_{1}$ generation (3.398) (Table 3).

The higher GCV value for parental lines indicates that the plant height of parental lines is better than $\mathrm{F}_{1}$ generation. Hence on the basis of this genotypic variance component staple length of $F_{1}$ may be improved by breeding for particular trait.

\subsection{Staple Strength}

The Table 2 reveals that the mean value for staple strength was maximum (31.043) for MNH-786 followed by NIBGE-115 and then Anti-sense tRep cocker-312. The mean value was minimum (24.043) for FH-1000.

The Table 2 reveals that the mean value was maximum (28.297) for MNH-786 $\times$ Anti-sense tRep cocker-312 followed by NIBGE-115 $\times$ Anti-sense tRep cocker-312 for staple strength. The mean value was minimum (24.793) for FH-1000 $\times$ Anti-sense tRep cocker-312.

These results showed that staple strength of F1 hybrids is almost equal to their parental material. In all three crosses the hybrid of MNH-786 is performing better for this trait.

The Table 3 showed that for staple strength the GV value was higher (6.083) for parental lines followed by the GV values of $F_{1}$ generation (3.225). The PV value was also higher (6.091) for parental lines followed by $F_{1}$ generation (3.243). The EV value was higher (0.018) for $F_{1}$ generation followed by parental lines $(0.008)$.

For staple strength GCV value was higher (9.012) for parental lines followed by $F_{1}$ generation (6.706). The PCV value was higher (9.017) for parental lines followed by $F_{1}$ generation (6.725). The ECV value was higher $(0.504)$ for $\mathrm{F}_{1}$ generation followed by parental lines $(0.323)$ (Table 3 ).

The high GV, PV, GCV and PCV values indicate that variation is present but we are not sure rather this variation is useful or not. Results suggest that $F_{1}$ must be use in future breeding program for improvement.

\subsection{Fiber Fineness}

Fiber fineness was maximum (4.8733) for NIBGE-115 followed by FH-1000 and then Anti-sense tRep cocker-312. 
The mean value was minimum (4.2467) for MNH-786(Table 2).

Maximum fiber fineness was observed (4.5733) for NIBGE-115 $\times$ Anti-sense tRep cocker-312 followed by FH-1000 $\times$ Anti-sense tRep cocker-312 for fiber fineness. The mean value was minimum (4.26) for MNH-786 $\times$ Anti-sense tRep cocker-312 (Table 3).

These results showed that fiber fineness of F1 hybrids is almost equal to their parental material. In all three crosses the hybrid of NIBGE-115 is performing better for this trait (Table 3).

The Table 3 showed that for fiber fineness the GV value was higher (0.089) for parental lines followed by the GV values of $\mathrm{F}_{1}$ generation $(0.030)$. The $\mathrm{PV}$ value was also higher (0.091) for parental lines followed by $F_{1}$ generation (0.030). The EV value was higher (0.002) for parental lines followed by $F_{1}$ generation ( 0.001$)$.

For fiber fineness GCV value was higher (6.757) for parental lines followed by $\mathrm{F}_{1}$ generation (3.938). The PCV value was higher (6.817) for parental lines followed by $F_{1}$ generation (3.981). The ECV value was higher (0.898) for parental lines followed by $F_{1}$ generation $(0.587)$ (Table 3 ).

The higher GCV value for parental lines indicates that the fiber fineness of parental lines is better than $F_{1}$ generation. Hence on the basis of this genotypic variance component Plant height of $F_{1}$ may be improved by breeding for particular trait.

\subsection{Yield of Seed Cotton}

The Table 3 reveals that the mean value for yield of seed cotton was maximum (95.747) for FH-1000 followed by NIBGE-115 and then MNH-786. The mean value was minimum (73.247) for Anti-sense tRep cocker-312.
The Table 3 reveals that the mean value was maximum (84.497) for FH-1000 $\times$ Anti-sense tRep cocker-312 followed by NIBGE-115 × Anti-sense tRep cocker-312 for yield of seed cotton. The mean value was minimum (76.117) for MNH-786 × Anti-sense tRep cocker-312.

These results showed that yield of seed cotton for F1 hybrid is almost equal to their parental material. In all three crosses the hybrid of FH-1000 is performing better for this trait (Table 2).

The Table 3 showed that for plant height the GV value was higher (88.194) for parental lines followed by the GV values of $F_{1}$ generation (8.738). The PV value was also higher (138.268) for parental lines followed by $F_{1}$ generation (37.032). The EV value was higher (50.074) for parental lines followed by $F_{1}$ generation (28.293).

For plant height GCV value was higher (11.112) for parental lines followed by $F_{1}$ generation (3.660). The PCV value was higher (13.913) for parental lines followed by $F_{1}$ generation (7.535). The ECV value was higher (8.373) for parental lines followed by $F_{1}$ generation (6.586) (Table 3).

The higher GCV value for parental lines indicates that the plant height of parental lines is better than $F_{1}$ generation. Hence on the basis of this genotypic variance component Plant height of $F_{1}$ may be improved by breeding for particular trait.

There was high heritability $(0.638)$ found for parental lines followed by $F_{1}$ generation (0.236). The high value of heritability of parents for plant height suggests that selection might be done among the parental genotypes.

The high GV, PV, GCV and PCV values indicate that variation is present but we are not sure rather this variation is useful or not. Results suggest that $F_{1}$ must be use in future breeding program for improvement. 
Table 2. Assessment of Viral Infection on Morphological Traits of parent lines and $F_{1}$ hybrids

\begin{tabular}{|c|c|c|c|c|c|c|c|c|c|c|c|}
\hline & Genotype & $\begin{array}{l}\text { Plant } \\
\text { Height }\end{array}$ & $\begin{array}{c}\text { Monopodial } \\
\text { Branches per Plant }\end{array}$ & $\begin{array}{c}\text { Sympodial Branches } \\
\text { per Plant }\end{array}$ & $\begin{array}{c}\text { Number of } \\
\text { Boll per Plant }\end{array}$ & $\begin{array}{c}\text { Lint } \\
\text { Percentage }\end{array}$ & $\begin{array}{c}\text { Boll } \\
\text { Weight }\end{array}$ & $\begin{array}{l}\text { Staple } \\
\text { Length }\end{array}$ & $\begin{array}{l}\text { Staple } \\
\text { Strength }\end{array}$ & $\begin{array}{c}\text { Fiber } \\
\text { Fineness }\end{array}$ & $\begin{array}{c}\text { Yield of Seed } \\
\text { Cotton }\end{array}$ \\
\hline \multirow{4}{*}{$\begin{array}{l}\text { Parent } \\
\text { Lines }\end{array}$} & MNH-786 & $106.78 \mathrm{~A}$ & $1.53 \mathrm{~A}$ & $20.53 \mathrm{~A}$ & $38.07 \mathrm{~A}$ & $38.38 \mathrm{~A}$ & $3.77 \mathrm{~A}$ & $35.187 \mathrm{~A}$ & $31.04 \mathrm{~A}$ & $4.87 \mathrm{~A}$ & $95.75 \mathrm{~A}$ \\
\hline & NIBGE-115 & $105.43 \mathrm{AB}$ & $1.4 \mathrm{~B}$ & $19.60 \mathrm{~B}$ & $36.733 \mathrm{AB}$ & $37.03 \mathrm{~B}$ & $3.77 \mathrm{~A}$ & $34.967 \mathrm{~A}$ & $28.74 \mathrm{~B}$ & $4.31 \mathrm{~B}$ & $90.10 \mathrm{AB}$ \\
\hline & FH-1000 & $100.63 \mathrm{BC}$ & $1.4 \mathrm{~B}$ & $18.00 \mathrm{C}$ & $35.07 \mathrm{AB}$ & $36.64 \mathrm{~B}$ & $3.71 \mathrm{~A}$ & $34.867 \mathrm{~A}$ & $25.65 \mathrm{C}$ & $4.27 \mathrm{~B}$ & $78.99 \mathrm{BC}$ \\
\hline & $\begin{array}{l}\text { Anti-sense tRep } \\
\text { cocker-312 }\end{array}$ & $96.80 \mathrm{C}$ & $1.4 \mathrm{~B}$ & $16.47 \mathrm{D}$ & $33.60 \mathrm{~B}$ & $34.64 \mathrm{C}$ & $3.57 \mathrm{~B}$ & $34.720 \mathrm{~A}$ & $24.04 \mathrm{D}$ & $4.25 \mathrm{~B}$ & $73.25 \mathrm{C}$ \\
\hline \multirow{3}{*}{$\begin{array}{c}\mathrm{F}_{1} \\
\text { Hybrids }\end{array}$} & $\begin{array}{l}\text { MNH-786 } \times \text { Anti-sense } \\
\text { tRep cocker-312 }\end{array}$ & $101.79 \mathrm{~A}$ & $1.47 \mathrm{~A}$ & $20.07 \mathrm{~A}$ & $35.83 \mathrm{~A}$ & $36.51 \mathrm{~A}$ & $3.77 \mathrm{~A}$ & $34.95 \mathrm{~A}$ & $28.30 \mathrm{~A}$ & $4.57 \mathrm{~A}$ & $84.50 \mathrm{~A}$ \\
\hline & $\begin{array}{l}\text { NIBGE1 } 15 \times \text { Anti-sense } \\
\text { tRep cocker-312 }\end{array}$ & $101.12 \mathrm{~A}$ & $1.40 \mathrm{~A}$ & $18.77 \mathrm{~B}$ & $35.17 \mathrm{~A}$ & $35.64 \mathrm{~B}$ & $3.74 \mathrm{AB}$ & $34.84 \mathrm{~A}$ & $27.24 \mathrm{~B}$ & $4.29 \mathrm{~B}$ & $81.66 \mathrm{~A}$ \\
\hline & $\begin{array}{l}\text { FH-1000 } \times \text { Anti-sense } \\
\text { tRep cocker-312 }\end{array}$ & $98.717 \mathrm{~A}$ & $1.40 \mathrm{~A}$ & $18.03 \mathrm{C}$ & $34.33 \mathrm{~A}$ & $35.50 \mathrm{~B}$ & $3.67 \mathrm{~B}$ & $34.79 \mathrm{~A}$ & $24.79 \mathrm{C}$ & $4.26 \mathrm{~B}$ & $76.12 \mathrm{~A}$ \\
\hline
\end{tabular}

Table 3. Components of variance and heritability for Morphological Traits of parent lines and $F_{1}$ hybrid

\begin{tabular}{|c|c|c|c|c|c|c|c|c|c|c|c|}
\hline & Genotype & $\begin{array}{l}\text { Plant } \\
\text { Height }\end{array}$ & $\begin{array}{c}\text { Monopodial } \\
\text { Branches per Plant }\end{array}$ & $\begin{array}{c}\text { Sympodial } \\
\text { Branches per Plant }\end{array}$ & $\begin{array}{c}\text { Number of } \\
\text { Boll per Plant }\end{array}$ & $\begin{array}{c}\text { Lint } \\
\text { Percentage } \\
\end{array}$ & Boll Weight & $\begin{array}{l}\text { Staple } \\
\text { Length }\end{array}$ & $\begin{array}{c}\text { Staple } \\
\text { Strength }\end{array}$ & $\begin{array}{c}\text { Fiber } \\
\text { Fineness }\end{array}$ & $\begin{array}{c}\text { Yield of Seed } \\
\text { Cotton }\end{array}$ \\
\hline \multirow{7}{*}{ Parent Lines } & GV & 10.521 & 0.002 & 1.943 & 1.325 & 1.445 & 0.004 & 0.896 & 6.083 & 0.089 & 88.194 \\
\hline & PV & 15.998 & 0.005 & 2.073 & 4.088 & 1.528 & 0.008 & 1.860 & 6.091 & 0.091 & 138.268 \\
\hline & EV & 5.476 & 0.003 & 0.130 & 2.763 & 0.083 & 0.004 & 2.756 & 0.008 & 0.002 & 50.074 \\
\hline & GCV & 3.167 & 2.791 & 7.475 & 3.209 & 3.278 & 1.669 & 0.001 & 9.012 & 6.757 & 11.112 \\
\hline & PCV & 3.905 & 4.958 & 7.720 & 5.637 & 3.371 & 2.370 & 3.904 & 9.017 & 6.817 & 13.913 \\
\hline & $\mathrm{ECV}$ & 2.285 & 4.098 & 1.930 & 4.635 & 0.787 & 1.683 & 4.752 & 0.323 & 0.898 & 8.373 \\
\hline & h2BS & 0.658 & 0.317 & 0.938 & 0.324 & 0.945 & 0.496 & 0.482 & 0.999 & 0.983 & 0.638 \\
\hline \multirow{7}{*}{$\mathrm{F}_{1}$ Hybrids } & GV & 1.286 & -0.001 & 1.038 & -0.137 & 0.272 & 0.002 & 0.461 & 3.225 & 0.030 & 8.738 \\
\hline & PV & 5.256 & 0.006 & 1.105 & 1.968 & 0.355 & 0.004 & 0.943 & 3.243 & 0.030 & 37.032 \\
\hline & EV & 3.970 & 0.007 & 0.067 & 2.104 & 0.083 & 0.002 & 1.404 & 0.018 & 0.001 & 28.293 \\
\hline & GCV & 1.128 & 0.001 & 5.375 & 0.0001 & 1.453 & 1.116 & 0.0005 & 6.706 & 3.938 & 3.660 \\
\hline & PCV & 2.280 & 5.495 & 5.545 & 3.995 & 1.660 & 1.702 & 2.785 & 6.725 & 3.981 & 7.535 \\
\hline & ECV & 1.982 & 5.857 & 1.362 & 4.131 & 0.804 & 1.284 & 3.398 & 0.504 & 0.587 & 6.586 \\
\hline & h2BS & 0.245 & -0.136 & 0.940 & -0.069 & 0.765 & 0.430 & 0.489 & 0.994 & 0.978 & 0.236 \\
\hline
\end{tabular}

GV (Genotypic variance),

PCV (Phenotypic coefficient of variance),

PV (Phenotypic variance),

GCV (Genotypic coefficient of variance),

EV (Environmental variance),

ECV (Environmental coefficient of variance),

$\mathrm{h}^{2}{ }_{\mathrm{BS}}$ (Broad sense Heritability) 


\section{Discussion}

Symptoms of CLCuD includes curling of leaf, swelling and darkening of vein and leaf enations underneath the leaves $[11,12]$. Infection to plant caused by CLCuD varies due to varietal difference, vector density and climatic factors in an area. Reduction in yield due to the adoption of tolerant varieties has been recorded up to $50 \%$ and in comparison growing of susceptible varieties reduced the yield to $85 \%-90 \%$ [13].

Various methodologies for genetically engineered resistance against geminiviruses have established successful such gene silencing [18]. Numerous approaches to control replication of geminiviruses have been established like RNA interference (RNAi) [26]. An approach has developed to express antisense transgenes complimentary to target mRNA Experimentation on different antisense transgens exhibited that specificity of resistance depended on the level of homology between the antisense RNA and the target virus sequence [15]. The technology of anti-sense RNAi has been effectively applied to engineer resistance. against geminiviruses $[16,17]$. However antisense is actually a part of complex natural pathways for gene regulation by homology sensing mechanism where sense transcripts are also able to silence gene expression [18]. Recently transgenic tobacco plants expressing geminiviral resistance to the $\mathrm{CLCuV}$, through the expression of truncated tAC1/tRep gene of CLCuV in sense and antisense orientation and blocked the replication of this virus done RNAi [15]. Broad-spectrum resistance could be produced by combining multiple sources of resistance, i.e. hybridization of naturally tolerant and genetically modified plants. This could be done by planning a breeding program involving transgenic plants with expressed tRep gene and naturally tolerant varieties already present in field [19].

Dongre and Bhandarkar [27] conduct study on 52 species of Gossypium, 48 are wild and four are cultivated which produce spinnable fiber. The cultivated species include two diploids, G. herbaceum L. and G. arboreum L., and two other, $G$. barbadense $L$. and $G$. hirsutum $L$ are tetraploids. The breeding programs are supported by the genetic diversity in commercially grown cotton cultivars and species. The evaluation of genetic diversity can be accomplished on the basis of morphological, physiological characteristics these results are in line with the Results of present study.

Cotton varieties that showed resistance against CLCuD were developed by intra-hirsutum crosses using FH-900, CIM-448 and LRA-5166 as tolerant parents and S-12 as susceptible varieties. The objective of this study was to find the pattern of variation in qualitative and quantitative traits in the presence of CLCuD. The study showed that tolerance is due to more than one gene as none of the crosses showed complete dominance or a distinct bimodal distribution [13].

Resistant $\mathrm{CLCuV}$ genotypes of cotton namely FH-682, CIM-240, CRIS-9, BH-36, CIM-109 and CIM-1100 were crossed in all possible combinations. For assessing the tolerance level, $F_{1}$ and $F_{2}$ generations were inoculated with whitefly. The $F_{1}$ and $F_{2}$ populationsfrom the crosses of CIM-1100 with other genotypes including reciprocal crosses shows $100 \%$ resistance level [20].

A study was conducted to combine natural and genetically engineered sources of resistance in Gossypium hirsutum $L$. against $\mathrm{CLCuD}$ and effect on fiber characters. It was concluded that tolerance level was higher in the hybrids of NIBGE-115 $\times$ transgenic Coker-312 expressing antisense rep, and the lowest level was found in the crossing combinations of FH-1000 $\times$ transgenic rep Coker- 312 cotton. The GOT\%; fiber fineness was significantly increased in F1 and F2 of NIBGE-115 $\times$ transgenic Coker-312 expressing antisense rep. Significant increase for fiber length was observed in the crosses of CIM-496 $\times$ transgenic Coker-312 expressing antisense rep [19].

The results reveals that the plant height, no. of sympodial branches/plant, no. of bolls/plant An experiment was conducted to evaluate the growth and yield performance of five cotton cultivars i.e. FH-113, FH-901, FH-115, FH-207 and MNH-786 under optimum conditions., boll weight, yield of seed cotton, GOT\%, fiber characteristics were significantly differs. The cultivar FH-115 showed best performance followed by MNH-786 [12]..

\section{REFERENCES}

[1] G. Ahmad, S. A L.), Asian Journal of Plant Science, Vol.6, 705-707, 2002.

[2] A. Abdullah. An Analysis of Bt Cotton Cultivation in Punjab, Pakistan Using the Agriculture Decision Support System (ADSS). Ag Bio Forum, Vol.3, 274-287, 2010.

[3] T. Mahmood, M. Arshad, . Malik, Z. Mahmood, M. Z. Iqbal, S. Ahmad. Effect of cotton leaf curl virus disease on morphology, yield and fibre characteristics of susceptible lines/cultivars of cotton (Gossypium hirsutum M. I. Gill, H. T. Mahmood, M. Tahir, S. Hussain. Burewala strain of cotton leaf curl virus: a threat to $\mathrm{CLCuV}$ cotton resistant varieties, Asian Journal of Plant Science, Vol.2, 968-970, 2003.

[4] R. M. Goodman. Single-stranded DNA genome in a whitefly-transmitted plant virus, Virology, Vol.83, 171-179, 1977.

[5] M. Lapidot, M. Friedmann. Breeding for resistance to whitefly - transmitted geminiviruses, Annuals of Applied Biology, Vol.140, 109-127, 2002.

[6] R. Vanitharani, P. Chellappan, C. M. Fauquet. Geminiviruses and RNA silencing. Trends of Plant Sciences, Vol.10, 144-151, 2005.

[7] C. Fauquet, R. Briddon, J. Brown, E. Moriones, J. Stanley, M. Zerbini, X. Zhou. Geminivirus strain demarcation and nomenclature, Archive of Virology, Vol.153, 783-821, 2008.

[8] S. Mansoor, I. Amin, S. Iram, M. Hussain, Y. Zafar, K. A. Malik, R. W. Briddon. Breakdown of resistance in cotton to cotton leaf curl disease in Pakistan, Plant Pathology, Vol.52, 
784-784, 2003.

[9] M. Padidam, R. N. Beachy, C. M. Fauquet. Classification and identification of geminiviruses using sequence comparisons, Journal of Gene Virology, Vol.76, 249-263, 1995.

[10] R. W. Briddon. Cotton leaf curl disease, a multicomponent begomovirus complex, Molecular Plant Pathology, Vol.4, 427-434, 2003.

[11] R. W. Briddon, S. Mansoor, I. D. Bedford, M. S. Pinner, K. Saunders, J. Stanley, Y. Zafar, K. A. Malik, P. G. Markham. Identification of DNA Components Required for Induction of Cotton Leaf Curl Disease, Virology, Vol.285, 234-243, 2001.

[12] F. Ehsan, A. Ali, M. A. Nadeem, M. Tahir, A. Majeed. Comparative yield performance of new cultivars of cotton (Gossypium hirsutum L.), Pakistan Journal of Life and Social Sciences, Vol.6, 1-3, 2008.

[13] A. Khan, M. Hussain, S. Rauf, T. Khan. Inheritance of resistance to Cotton leaf curl virus in cotton (Gossypium hirsutum L.), Plant Production Sciences, Vol.43. 455-460, 2007.

[14] F. Tenllado, C. Llave, J. R. Díaz-Ruíz. RNA interference as a new biotechnological tool for the control of virus diseases in plants, Virus Research, Vol.102, 85-96, 2004.

[15] S. Asad, W. Haris, A. Bashir, Y. Zafar, K. Malik, N. Malik, C. Lichtenstein. Transgenic tobacco expressing geminiviral RNAs are resistant to the serious viral pathogen causing cotton leaf curl disease, Archive of Virology, Vol.148, 2341-2352, 2003.

[16] E. R. Bejarano, C. P. Lichtenstein, Expression of TGMV antisense RNA in transgenic tobacco inhibits replication of BCTV but not ACMV geminiviruses, Plant Molecular Biology, Vol.24, 241-248, 1994.

[17] M. Bendahmane, B. Gronenborn. Engineering resistance against tomato yellow leaf curl virus (TYLCV) using antisense RNA. Plant Molecular Biology, Vol.33, 351-357,
1997.

[18] M. Matzke, A. J. M. Matzke, J. M. Kooter. RNA: Guiding Gene Silencing. Science, Vol.293, 1080-1083, 2001.

[19] M. T. Azhar, S. Aftab, Y. Zafar, S. Mansoor. Utilization of natural and genetically-engineered sources in Gossypium hirsutum for the development of tolerance against cotton leaf curl disease and fiber characteristics, International Journal of Agricultural Biology, Vol.12, 744-748, 2010.

[20] N. U. Khan, G. Hassan, M. Kumbhar. African Crop Science Conference Proceedings, Egypt, 2007.

[21] C. Beasley, I. P. Ting. The effects of plant growth substances on in vitro fiber development from fertilized cotton ovules, American Journal of Botany, 130-139, 1973.

[22] K. P. Akhtar, S. Haidar, M. K. R. Khan, M. Ahmad, N. Sarwar, M. A. Murtaza, M. Aslam. Evaluation of Gossypium species for resistance to cotton leaf curl Burewala viru. Annuals of Applied Biology, Vol.157, 135-147, 2010.

[23] R. G. D. Steel, J. H. Torrie, D. A. Dickey. Principles and Procedures of Statistics. A biometrical approach. 3rd Ed., McGraw Hill Book Co., USA, 1997.

[24] Y. Li, s. Kajita, S. Kawai, Y. Katayama, N. Mohoshi. Down-regulation of an anionic peroxidase in transgenic aspen and its effect on lignin characteristics, Journal of Plant Research, Vol.116, 175-182, 2003.

[25] J. Hashmi, Zafar, Y. Arshad, M. Mansoor, S. Asad. Engineering cotton (Gossypium hirsutum L.) for resistance to cotton leaf curl disease using viral truncated AC1 DNA sequences, Virus Genes, Vol42, 286-296, 2011.

[26] M. Williams, G. Clark, K. Sathasivan,A. S. Islam. RNA Interference and its Application in Crop Improvement. Plant tissue culture and Biotechnology, Vol.1, 18-25, 2004.

[27] A. Dongre, M. Bhandarkar. Genetic diversity in tetraploid and diploid cotton (Gossypium spp.) using ISSR and microsatellite DNA markers, Indian Journal of Biotechnology, Vol.6, 349-353, 2007. 